\title{
Post-Stroke Depression at Teaching Hospital Center of Libreville
}

\author{
I. A. Camara ${ }^{*}$, C. M. Coulibaly², N. Diouf Mbourou1, P. M. Gnigone'1, G. A. G. Mambila Matsalou1, \\ A. Nsounda Mandzela1 ${ }^{1}$, L. Oura ${ }^{3}$, J. Nyangui Mapaga ${ }^{1}$, U. D. Kombila ${ }^{4}$, M. M. Moubecka ${ }^{1}$, P. N. Kouna ${ }^{1}$
}

${ }^{1}$ Neurology of the CHUL, Libreville, Gabon

${ }^{2}$ Polyclinic, ELRAPHA, Libreville, Gabon

${ }^{3}$ Neurology of HIAOBO, Libreville, Gabon

${ }^{4}$ Internal Medicine of CHUL, Libreville, Gabon

Email: ^ibrahaissata@yahoo.fr

How to cite this paper: Camara, I.A., Coulibaly, C.M., Diouf Mbourou, N., Gnigone, P.M., Mambila Matsalou, G.A.G., Nsounda Mandzela, A., Oura, L., Nyangui Mapaga, J., Kombila, U.D., Moubecka, M.M. and Kouna, P.N. (2018) Post-Stroke Depression at Teaching Hospital Center of Libreville. Open Access Library Journal, 5: e5049.

https://doi.org/10.4236/oalib.1105049

Received: November 15, 2018

Accepted: December 25, 2018

Published: December 28, 2018

Copyright $\odot 2018$ by authors and Open Access Library Inc.

This work is licensed under the Creative Commons Attribution International License (CC BY 4.0).

http://creativecommons.org/licenses/by/4.0/

\begin{abstract}
Introduction: Post-stroke depression occurs in a context of stroke characterized by sadness, loss of interest, feelings of guilt, loss of appetite, a feeling of tiredness, and a lack of concentration. Material and Methods: We conducted a descriptive cross-sectional study from January 1, 2013 to September 30, 2016. For the diagnosis of post-stroke depression, neuropsychological tests (DSM-IV and MADRS) were used. The collection approach was a maintenance survey followed by an examination. Results: From 153 stroke patients, 48.4\% $(n=74)$ had post-stroke depression. Depressed mood was noted in $50.3 \%$ and $43.8 \%$ had a marked decrease in interest. $67.9 \%$ of these patients had a primary level of education. Widows had 4.2 times the risk of post-stroke depression, and married and retired patients were 3 times more likely than public servants. The occurrence of post-stroke depression was significantly related to the presence of motor deficit in our patients, $\mathrm{p}<0.0001$. Conclusion: These results suggest that the risk of developing depression after stroke increases with the motor deficit. The DSM-IV and MADRS scores remain neuropsychological examinations of choice for the diagnostic approach.
\end{abstract}

\section{Subject Areas}

Neurology, Public Health

\section{Keywords}

Depression, Stroke, Libreville

\section{Introduction}

Post-stroke depression (CVA) is the most common psychiatric event after a 
stroke and is defined as depression occurring in a stroke context. Significant in terms of its social implications for the quality of life, as well as the patient's potential motor recuperation, its estimated prevalence is $30 \%$ to $35 \%$ with extremes ranging from $20 \%$ to $60 \%$ worldwide [1]. In Europe, according to a 2013 study in Belgium by A. De Ryck, the prevalence is between $19.8 \%$ and 28.3\% [2]. Data on DPAVC in Africa are scarce. In Burkina Faso, Napon et al. reported a frequency of $38.9 \%$ for 167 patients [1], while in Cotonou, Houinato et al. found a prevalence of $87.7 \%$ in 2006 [3]. In Bangui, Mbelesso et al. conducted a study in two central hospitals for 6 months. The prevalence of DPAVC found in hospitalized patients was $88.6 \%$ [4].

In Gabon, stroke is the leading cause of hospitalization in our neurology services, with an overall prevalence of $42.9 \%$ [5] and data on DPAVC are unavailable justifying the purpose of this study.

The main objective of this study was to evaluate the prevalence of DPAVC and to determine the sociodemographic characteristics associated with this condition at the University Hospital Center of Libreville.

\section{Methodology}

We conducted a descriptive cross-sectional observational study in the neurology department during the period from January 2013 to September 30, 2016.

Included in this study were patients who had suffered cerebrovascular accidents for more than one month regardless of type (deficiencies, infarction or hemorrhage), confirmed with cerebral imaging (CT or MRI) and followed in the neurology department of the CHUL. This study excluded patients with neuropsychiatric disorders who had a severe language impairment that impeded the success of the survey.

We used the following tests for the diagnosis of depression:

- The Diagnostic and Statistical Manual of Mental Disorders (DSM-IV), diagnosed with depression for a score greater than or equal to 5/9;

- The Montgomery and Asberg Depression Rating Scale (MADRS) assesses the severity of depression for a total greater than $16 / 60$ is considered abnormal and a total greater than $30 / 60$ is considered a severe depression.

The study involved 155 patients and was conducted during the consultation and inpatient days for patients with a history of stroke. We conducted a medical file review to contact the patients followed by an interview with the patients. The Chi-2 test was used for frequency comparison and the Student test for the comparison of averages. A result was statistically significant for $\mathrm{p}<0.05$. The study of associated factors was done according to the logistic regression model in uni and multi-variate analysis.

\section{Results}

\section{Diagnosis of depression}

Depressed mood was noted in $50.3 \%$ of patients and $43.8 \%$ had a marked 
decrease in interest or pleasure, significant loss or weight gain as presented in Table 1.

Prevalence of depression and its severity

Of the 153 patients surveyed, 74 had a score on the Montgomery-Asberg scale $\geq 16$. The prevalence of depression was $48.4 \%$ (Table 2, Table 3 ).

Sociodemographic characteristics

Profession, living environment, seniority of diagnosis and social security

Post stroke depression was significantly associated with the patient occupation $(p=0.036)$. Retired patients had 3 times the risk of depression after stroke as officials (Table 4).

Clinical aspects

\section{Sequential motor deficiency}

DPAVC was significantly associated with the presence of motor deficit $(\mathrm{p}=$ 0.000) (Table 5).

\section{Discussion}

The prevalence of DPAVC was determined and associated factors identified. The prevalence of DPAVC at Libreville University Hospital was estimated at $48.4 \%$. Associated factors were multiple. These factors included marital status, motor deficit and educational attainment. Our study allowed us to profile patients with

Table 1. Distribution of stroke patients by DSM-IV items for diagnosis of depression.

\begin{tabular}{ccc}
\hline Variables & Workforce & Proportion $(\%)^{*}$ \\
\hline Depressed mood & 77 & 50.3 \\
Marked decrease in interest, pleasure & 67 & 43.8 \\
Significant loss or weight gain in the absence of diet & 67 & 43.8 \\
Insomnia or hypersomnia & 55 & 35.9 \\
Agitation or psychomotor retardation & 67 & 43.8 \\
Fatigue or loss of energy & 59 & 38.6 \\
Sense of worthlessness or excessive or inappropriate guilt & 55 & 35.9 \\
Decreased ability to think or concentrate or indecision & 43 & 28.1 \\
Thoughts of recurring death & 21 & 13.7 \\
\hline
\end{tabular}

${ }^{\star}$ Each proportion was calculated in relation to $\mathrm{N}=153$.

Table 2. Distribution of stroke patients using montgomery-asberg scale scores to assess the severity of depression.

\begin{tabular}{ccc}
\hline Variables & Workforce & Proportion (\%) \\
\hline No depression $(<16)$ & 79 & 51.6 \\
Depression minor $(16-30)$ & 56 & 36.6 \\
Major depression $(>30)$ & 18 & 11.8 \\
Total & 153 & 100.0 \\
\hline
\end{tabular}


Table 3. Specific prevalence of DPAVC by characteristics demographics.

\begin{tabular}{ccccccc}
\hline Variables & Total (N) & DPAVC $\mathbf{n} \%$ & OR & IC $_{95 \%}$ & P \\
\hline Gender & & & & & & 0.609 \\
Man & 88 & 41 & 46.6 & 1 & & \\
Female & 65 & 33 & 50.8 & 1.2 & $0.6-2.4$ & \\
Age (year) & & & & & & 0.069 \\
$\leq 39$ & 9 & 2 & 22.2 & 1 & & \\
$40-49$ & 32 & 15 & 46.9 & 3.1 & $0.6-17.2$ & 0.262 \\
50 - 59 & 56 & 23 & 41.1 & 2.4 & $0.5-12.8$ & 0.463 \\
$\geq 60$ & 56 & 34 & 60.7 & 5.4 & $1.0-28.5$ & 0.073 \\
Education level & & & & & & 0.002 \\
Primary & 53 & 36 & 67.9 & 3.1 & $1.1-8.5$ & 0.029 \\
Secondary & 78 & 29 & 37.2 & 0.9 & $0.3-2.2$ & 0.750 \\
Academic university & 22 & 9 & 40.9 & 1 & & \\
Marital status & & & & & & 0.048 \\
Married (e) & 57 & 25 & 43.9 & 1 & & \\
Single & 46 & 18 & 39.1 & 0.8 & $0.4-1.8$ & 0.628 \\
Cohabitation & 33 & 18 & 54.5 & 1.5 & $0.6-3.6$ & 0.328 \\
Widowed & 17 & 13 & 76.5 & 4.2 & $1.2-14.3$ & $\mathbf{0 . 0 1 8}$ \\
Residence & & & & & & 0.085 \\
Urban & 137 & 63 & 46.0 & 1 & & \\
Rural & 16 & 11 & 68.8 & 2.6 & $0.8-9.1$ & \\
\hline & & & & & & \\
\hline
\end{tabular}

Table 4. Distribution of patients with DPAVC by occupation, seniority of stroke and social coverage.

\begin{tabular}{ccccccc}
\hline Variables & Total $(\mathrm{N})$ & DPAVC $\mathrm{n} \%$ & OR & IC $_{95 \%}$ & $\mathrm{p}$ \\
\hline Occupation & & & & & & 0.036 \\
Official & 28 & 10 & 35.7 & 1 & & \\
Private setting & 18 & 5 & 27.8 & 0.7 & $0.2-2.5$ & 0.575 \\
Merchant & 10 & 2 & 20.0 & 0.4 & $0.1-2.5$ & 0.453 \\
Artisan & 4 & 3 & 75.0 & 1.4 & $0.3-7.3$ & 1.000 \\
Housewife & 3 & 2 & 66.7 & 3.6 & $0.3-44.8$ & 0.543 \\
Restated & 40 & 25 & 62.5 & 3.0 & $1.1-8.2$ & 0.030 \\
Unemployed & 50 & 27 & 54.0 & 2.1 & $0.8-5.5$ & 0.123 \\
Living environment & & & & & & 0.064 \\
With the family & 145 & 73 & 50.3 & 7.1 & $0.8-157.8$ & \\
Only & 8 & 1 & 12.5 & 1 & & 0.519 \\
Stroke seniority (year) & & & & & & \\
1 - 4 & 125 & 62 & 49.6 & 1.3 & $0.5-3.2$ & \\
5 - 8 & 28 & 12 & 42.9 & 1 & & \\
PES & 125 & 64 & 51.2 & 1 & & \\
Yes * & 28 & 10 & 35.7 & 1.8 & $0.7-4.6$ & \\
No & & & & & & \\
\hline
\end{tabular}

${ }^{*}$ Patients whose social care (PES) is insured by the National Fund for Health and Social Welfare (CNAMGS) or other. 
Table 5. Distribution of patients by Post-AVC Depression and existence or type of motor deficit.

\begin{tabular}{|c|c|c|c|c|c|c|}
\hline Variables & $\begin{array}{l}\text { Total } \\
(\mathrm{N})\end{array}$ & \multicolumn{2}{|c|}{$\begin{array}{c}\text { DPAVC } \\
\mathrm{n} \%\end{array}$} & OR & $\mathrm{IC}_{95 \%}$ & $\mathrm{p}$ \\
\hline Absent & 20 & 2 & 10.0 & 1 & & \\
\hline Present & 133 & 72 & 54.1 & 10.6 & $2.2-69.1$ & \\
\hline Type of motor deficit & & & & & & 0.010 \\
\hline No motor deficit & 20 & 2 & 10.0 & 1 & & \\
\hline Right hemiparesis & 39 & 17 & 43.6 & 6.9 & $1.4-34.2$ & 0.001 \\
\hline Left hemiparesis & 30 & 16 & 53.3 & 10.3 & $2.0-52.4$ & 0.002 \\
\hline Right hemiplegia & 21 & 14 & 66.7 & 18.0 & $3.2-100.5$ & 0.000 \\
\hline Left hemiplegia & 18 & 13 & 72.0 & 23.4 & $3.9-139.9$ & 0.000 \\
\hline $\begin{array}{l}\text { Straight predominantly brachio-facial } \\
\text { hemiparesis }\end{array}$ & 12 & 5 & 41.7 & 6.4 & $1.0-41.2$ & 0.098 \\
\hline $\begin{array}{l}\text { Left predominantly brachio-facial } \\
\text { hemiparesis }\end{array}$ & 8 & 4 & 50.0 & 9.0 & $1.2-67.4$ & 0.069 \\
\hline Predominantly crural right hemiparesis & 3 & 2 & 66.7 & 18.0 & $1.1-299.0$ & 0.110 \\
\hline Predominantly left left hemiparesis & 2 & 1 & 50.0 & 9.0 & $0.4-206.5$ & 0.260 \\
\hline
\end{tabular}

post stroke depression. Thus, he can be defined as being a patient having on average 56 years, having a motor deficit, a level of primary education and widowed (widowed).

\section{Prevalence of post-stroke depression at Libreville Hospital}

The average prevalence of DPAVC is high. It is estimated at around 30\% $35 \%$, with extremes ranging from $20 \%$ to $60 \%$ [6]. In our study, the prevalence of DPAVC was evaluated at $48.4 \%$. This frequency is high compared to those obtained by some authors. In particular, Ning Sun et al. in China in 2014, Christian Napon et al. in Burkina Faso in 2012 [1] [7] who respectively found a prevalence of $31.4 \% ; 38.9 \%$. On the other hand, Mbelesso et al. in Central Africa in 2012 [4] found a prevalence of $88.6 \%$. However, this great variability in the prevalence rate $(20 \%$ to $60 \%)$ of the DPAVC is mainly due, according to Paolucci et al. [6] the methodology used including the diagnostic criteria, the type of depression scale, and the time to assessment of the patient after the stroke.

Sociodemographic characteristics associated with post stroke depression - Age

The mean age was estimated at $56.7 \pm 12.1$ years with a predominance of patients over 60 years of age, or $60.7 \%$. This age is similar to that found by Mapoure et al. [8] in Douala which was $58.66 \pm 13$ years old. Sagui et al. [9] in Senegal had shown an age of $61.9 \pm 12.4$. Although there is no significant relationship between age and depression, we note that the prevalence of depression increases with the 
age of the patients. Our data are consistent with those reported in 2014 by Mpembi Nkosi et al. in Kinshasa [10], which reveal an association between depression and patients over 65 years old. Our results are superimposable to those obtained by Mihajlo Tome Glamcevski II et al. in 2005 in Malaysia [11] where the average age was 58.6 years (standard deviation 12.5) and that in 2012 by Christian Napon et al. in Burkina [1] where the average age was 56.9 years with extremes of 29 and 84 years. Age is the most powerful, unmodifiable risk factor, since it is estimated that the risk of adult stroke doubles every decade after age 55 [12].

\section{- Gender}

In our study, we found that $50.8 \%$ of depressed patients were female, a sex ratio of 1.2. These results are consistent with those of Oladiji JO et al. in Nigeria in 2009 and Napon C in Burkina Faso in 2012 [1] [13] respectively of 0.62 and 0.9. There was no significant difference in the prevalence of post-stroke depression among men compared to women.

In Nigeria, data from a study by Imarhiagbe et al. in 2015 [14] revealed a male predominance with a significant link between depression and the male sex. This result may be due to the high proportion of male population in this study. Some studies have found no link between sex and depression after stroke, while others have found a link between them [15]. De Ryck A. et al. in 2014 in Belgium [2] observed in a prospective study of the multifactorial nature of vascular depression that the number of women with depression was much higher during the study period. Zhang et al. in China, Alajbegovic A et al. in Thailand [16] [17] had similar results showing that the female sex was predictive of the risk of DPAVC. Moreover, outside of a stroke context, female sex was found in a 2003 meta-analysis as a risk factor for depression [18]. The impact of a disability is all the more important for women because of their social functions, but also because of the poor aesthetic prognosis that can result. Poynter B. et al. in Canada in 2009 [19] showed in a meta-analysis of 47 published studies, that the prevalence of depression is high in both sexes with a rapid onset in women.

\section{- Level of education}

In our study, we found a significant relationship between educational attainment and depression. In addition, among patients with depression, there was a high frequency of patients with a primary education level of $67.9 \%$. This is consistent with the study conducted in 2009 in Brazil by Francisco Javier Carod-Artal et al. who also found a link between educational level and depression [20]. Depression would occur according to their study in patients with a low level of education. Another study conducted this time in Poland by Sienkiewicz-Jarosz et al. 2010 [21] and including 160 patients also reported an association between the DPAVC and the low level of study. On the other hand, $\mathrm{Yu}$ Zhang et al. found no relationship between educational attainment and depression in their 2016 study in Shanghai [22]. The low level of schooling is an exposure factor. Indeed, the lack of understanding of the pathology of stroke and 
the significant financial cost that may result from it in our context in developing countries may explain why the low level of schooling that may reflect the condition social exposure is an exposure factor of the DPAVC [23].

\section{- Marital status}

Marital status was singularly dominated by widowed subjects, ie $76.5 \%$ of cases $(\mathrm{p}=0.018)$. Widowed patients were 4 times more likely to have DPAVC. Francisco Javier CA [20] in his study found that being married would be an important factor associated with depression in Brazilian stroke patients. On the other hand, this observation differs from that of Yingying Yue et al. in 2015 [24] who found no link between marital status and depression in their study in China. Similarly, Rufus O. Akinyemi et al. in 2015 [25] found no link in their study conducted in Nigeria between marital status and the occurrence of depression after a stroke.

\section{- Occupation}

In Gabon, there is an increase in life expectancy and the number of retired people is also increasing. But, like other developing countries, changes affecting older people affect their living conditions more.

During our study, the DPAVC interested all socio-professional groups.

DPAVC was significantly associated with the profession of patients. Retirees were in the majority, $62.5 \%(\mathrm{p}=0.03)$. Retired patients were 3 times more likely to develop depression after stroke than staff members.

Ning Sun et al. in 2014 in China [7] found no link between depression and profession. This could be explained in our context by the fact that retirees, who for the most part have no source of income, are spending a lot of money on health maintenance. Tapping into resources for a good retirement makes them more likely.

\section{- Way of life}

Of the 74 cases of depression, $63.2 \%$ had a concomitant enolic impregnation and a sedentary lifestyle $(p=0.018)$ and $66.7 \%$ were sedentary $(p=0.003)$. A sedentary lifestyle was probably related to sequel motor deficiency or socio-occupational inactivity.

By analogy, Mpembi Nkosi et al. in Kinshasa in 2014 [10], in a study on the clinical course of the DPAVC, found an association between alcohol intake and depression $(p=0.048)$ and who was no longer in the year of after $(p=0.612)$. Ndzana in Cameroon [26] found that frequent alcohol consumption was statistically associated with the risk of DPAVC. In contrast, studies published by Yu Zhang et al. 2016 and Sai-Yu et al. in 2014 [22] [27] showed that there was no association between depression and risk factors such as alcohol and tobacco.

\section{- History}

In our study, we found an association between depression and antecedents ( $\mathrm{p}$ $=0.009$ ), especially since patients with hypertension and stroke as antecedents had 23.3 times more depression than the rest $(\mathrm{p}=0.001)$. Stroke helps to degrade the social health of the patient because of the sequelae that it causes. It 
can therefore alone be involved in the onset of depression and especially as it is severe [23]. The presence of hypertension was also strongly correlated with the occurrence of depression in the study by Rufus O. Akinyemi et al. in 2014 in Nigeria ( $p=0.001)$ [25]. Yu Zhang in 2016 [22] also found a correlation between depression and high blood pressure. Man-Van Ginkel et al. [28] have highlighted the personal antecedents of the DPAVC as a predictor of depression in the aftermath of a stroke. On the other hand, Annemieke De Ryck et al. in a systematic review of the literature in 2014 [29] did not report any link between cardiovascular diseases and the occurrence of depression after a stroke. The combination of hypertension and depression in our context, could be explained by the growing number of hypertensive people who have had a stroke. Stroke is a life event considered stressful. Then, when coupled with other life events, it is not uncommon to lead to a DPAVC [23].

Clinical aspects

\section{- Depression based on types of imaging and stroke}

We found no link between stroke depression and the type of examination performed. The only findings are the predominance of ischemic stroke and the achievement of cerebral CT. R. Vibo in 2007 [30] testified that stroke types have no significant influence on depression after stroke.

\section{- Sequential motor deficiency}

Motor disability is a determinant in the occurrence of DPAVC. In fact, the sudden relative loss (paresis) or total loss (paralysis) of the use of one of the limbs constitutes a heavy moral burden for the patient who sees himself losing his autonomy [23]. Hackett and Anderson [31] and Johnson et al. [32] reported in a review of the literature that the presence of a physical disability was a risk factor for DPAVC. Mpembi et al. in Congo [33] also found motor disability as a significant predictor of DPAVC $(\mathrm{p}=0.006)$.

Our study noted the same fact. DPAVC was significantly associated with the presence of motor deficit $(p=0.000)$. According to some authors [34], severe disability indicates significant brain damage and involvement of the brain regions responsible for mood. Compared with independent patients, physically disabled patients with stroke may experience more social and financial change and may be more sensitive to such changes [35].

\section{- Recidivism}

Our study found a statistically significant relationship between recurrent stroke and the onset of depression. Recurring patients were 7.9 times more likely to develop depression than those with no recurrence.

Motor disability, daily third-party addiction, and psychological stress experienced during and after stroke may explain the risk of post-stroke depression 7.9 times higher in those who have had a recurrence.

\section{Conclusion}

This preliminary study allowed us to evaluate the prevalence of post-stroke 
depression at Libreville University Hospital. It was $48.4 \%$. The profile of a depressive patient after a stroke in the neurology department of the University Hospital of Libreville is as follows: he was a patient suffering from stroke for more than a month or so and presenting with a depressed mood, a low level of education, widowhood, and a motor deficit. The diagnosis of depression is made according to DSM IV criteria.

\section{Conflicts of Interest}

The authors declare no conflicts of interest regarding the publication of this paper.

\section{References}

[1] Napon, C., Kaboré, A. and Kaboré, J. (2012) Post-Stroke Stroke Depression in Burkina Faso. Pan African Medical Journal, 13, 3.

[2] Ryck, A., Fransen, E., Brouns, R., et al. (2014) Post Stroke Depression and Its Multifactorial Nature: Results from a Prospective Longitudinal Study. Journal of the Neurological Sciences, 347, 159-166. https://doi.org/10.1016/j.jns.2014.09.038

[3] Houinato, D., Adjien, C., N’Goran, A. and Avode, D.G. (2007) Stroke and Depression in Hospitals in Cotonou (Benin). Neurological Review, 163, 13.

[4] Mbelesso, P., Senekian, V.P., Yangatimbi, E., et al. (2014) Post Stroke Depression in Africa: Myth or Reality. Bulletin de la Société de Pathologie Exotique, 107, 350-355. https://doi.org/10.1007/s13149-014-0399-9

[5] Kouna Ndouongo, P., Millogo, A., Siemofo Kangang, F.D.P. and Assengone-Zeh, Y. (2007) Epidemiological and Evolutionary Aspects of Stroke at the Hospital Center of Libreville (Gabon). AJNS, 12-17.

[6] Paolucci, S., Gandolfo, C., Provinciali, L., et al. (2005) Quantification of the Risk of Post-Stroke Depression: The Italian Multicenter Study DESTRO. Acta Psychiatrica Scandinavica, 112, 272-278. https://doi.org/10.1111/j.1600-0447.2005.00590.x

[7] Sun, N., Li, Q.-J., Lv, D.-M., Man, J., Liu, X.-S. And Sun, M.-L. (2014) A Survey on 465 Patients with Post-Stroke Depression in China. Archives of Psychiatric Nursing, 28, 368-371. https://doi.org/10.1016/j.apnu.2014.08.007

[8] Mapoure, Y.N., Kuate, C., Tchaleu, C.B., et al. (2014) Stroke Epidemiology in Douala: Three Years Prospective Study in a Teaching Hospital in Cameroon. World Journal of Neuroscience, 4, 406-414. https://doi.org/10.4236/wjns.2014.45044

[9] Sagui, E., M'baye, P.S., Dubecq, C., et al. (2005) Ischemic and Hemorrhagic Strokes in Dakar, Senegal. Stroke, 36, 1844-1847. https://doi.org/10.1161/01.STR.0000177864.08516.47

[10] Mpembi Nkosi, M., Mampunza Ma Miezi, S., Massamba Kubuta, V., et al. (2014) Clinical Evolution of Post-Stroke Stroke Depression in Kinshasa. Neurological Review, 170, 614-620.

[11] Glamcevski II, M.T. and Pierson, J. (2005) Prevalence of and Associated Factors with Post Stroke Depression: A Malaysian Study. Journal of Stroke and Cerebrovascular Diseases, 14, 157-161. https://doi.org/10.1016/j.jstrokecerebrovasdis.2005.03.006

[12] Nyangui Mapaga, J. (2015) Prognosis of Stroke in Libreville. PhD Thesis in Medicine. Faculty of Medicine and Health Sciences, Libreville.

[13] Oladiji, J.O., Akinbo, S.R., Aina, O.F. and Aiyejusunle, C.B. (2009) Risk Factors of 
Post-Stroke Depression among Stroke Survivors in Lagos, Nigeria. African Journal of Psychiatry, 12, 47-51. https://doi.org/10.4314/ajpsy.v12i1.30278

[14] Imarhiagbe, F.A. and Owolabi, A. (2015) Post Stroke Depression in a Sub Saharan Africans: Validation of the Japanese Stroke Scale for Depression. Sahel Medical Journal, 18, 121-125. https://doi.org/10.4103/1118-8561.169285

[15] Ojagbemi, A., Owolabi, M., Atalabi, M. and Baiyewu, O. (2013) Stroke Lesions and Post Stroke Depression among Survivors in Ibadan, Nigeria. African Journal of Medicine and Medical Sciences, 42, 245-251.

[16] Zhang, W.-N., Pan, Y.-H., Wang, X.-Y. and Zhao, Y. (2013) A Prospective Study of the Incidence and Correlated Factors of Post-Stroke Depression in China. PLoS ONE, 8, 78-81. https://doi.org/10.1371/journal.pone.0078981

[17] Alajbegovic, A., Djelilovic-Vranic, J., Alajbegovic, S., Nakicevic, A. and Todorovic, L. (2014) Tiric-Campara Post Stroke Depression. Medical Archives, 68, 47-50. https://doi.org/10.5455/medarh.2014.68.47-50

[18] Cole, M. and Dendukuri, N. (2003) Risk Factors for Depression in Elderly Subjects: A Systematic Review and Meta-Analysis. American Journal of Psychiatry, 160, 1147-1156. https://doi.org/10.1176/appi.ajp.160.6.1147

[19] Poynter, B., Shuman, M., Diaz-Granados, N., Kapral, M., Grace, S.L. and Stewart, D.E. (2009) Sex Differences in the Prevalence of Post-Stroke Depression: A Systematic Review. Psychosomatics, 50, 563-569. https://doi.org/10.1016/S0033-3182(09)70857-6

[20] Carod-Artal, F.J., Ferreira Coral, L., Trizotto, D.S. and Moreira Menezes, C. (2009) Poststroke Depression: Prevalence and Determinants in Brazilian Stroke Patients. Cerebrovascular Diseases, 28, 157-165. https://doi.org/10.1159/000226114

[21] Sienkiewicz-Jarosz, H., Milewska, D., Bochyńska, A., et al. (2010) Predictors of Depressive Symptoms in Patients with Stroke-A Three-Month Follow-Up. Neurologia i Neurochirurgia POLSKA, 44, 113-120. https://doi.org/10.1016/S0028-3843(14)60402-3

[22] Zhang, Y., Cheng, L., Chen, Y., Yang, G.Y., Liu, J. and Zeng, L. (2016) Clinical Predictor and Circulating microRNA Profile Expression in Patients with Early Onset Post-Stroke Depression. Journal of Affective Disorders, 193, 51-58. https://doi.org/10.1016/j.jad.2015.12.061

[23] Ngateu Bang, G.T. (2015) Predictors of Mental Depression after a Cerebral Vascular Accident in Yaounde. Doctoral Thesis in Medicine, Faculty of Medicine and Biomedical Sciences, Yaoundé I.

[24] Yue, Y., Rui, L., Lu, J., et al. (2015) Reliability and Validity of a New Post-Stroke Depression in Chinese Population. Journal of Affective Disorders, 174, 317-323. https://doi.org/10.1016/j.jad.2014.11.031

[25] Akinyemi, R.O., Allan, L., Owolabi, M.O., et al. (2014) Profile and Determinants of Vascular Cognitive Impairment in African Stroke Survivors: The CogFAST Nigeria Study. Journal of the Neurological Sciences, 346, 241-249. https://doi.org/10.1016/j.jns.2014.08.042

[26] NdzanaTsanga, J.B. (2013) Mental Depression in People with a Cerebral Vascular Accident Followed at Central Hospital of Yaoundé. PhD Thesis in Medicine, Faculty of Medicine and Biomedical Sciences, Yaoundé I.

[27] Cheng, S.Y., Zhao, Y.D., Li, J., Chen, X.Y., Wang, R.D. and Zeng, J.W. (2014) Plasma Levels of Glutamate during Stroke Is Associated with Development of Post-Stroke Depression. Psychoneuroendocrinology, 47, 126-135.

https://doi.org/10.1016/j.psyneuen.2014.05.006 
[28] Man-van Ginkel, J.M., Hafsteinsdottir, T.B., Lindeman, E., Ettema, R.G., Grobbee, D.E. and Schuurmans, M.J. (2013) In-Hospital Risk Prediction for Post-Stress Depression: Development and Validation of the Post-Stroke Depression Prediction Scale. Stroke, 44, 2441-2445. https://doi.org/10.1161/STROKEAHA.111.000304

[29] De Ryck, A., Brouns, R., Geurden, M., Elseviers, M., De Deyn, P.P. and Engelborghs, S. (2014) Risk Factors for Post Stroke Depression: Identification of Inconsistencies Based on a Systematic Review. Journal of Geriatric Psychiatry and Neurology, 27, 147-158. https://doi.org/10.1177/0891988714527514

[30] Vibo, R., Korv, J. and Roose, M. (2007) One-Year out after First-Ever Stroke According to Stroke Subtype, Severity, Risk Factors and Pre-Stroke Treatment. A Population-Based Study from Tartu, Estonia. European Journal of Neurology, 14, 435-439. https://doi.org/10.1111/j.1468-1331.2007.01704.x

[31] Hackett, M.L. and Anderson, C.S. (2005) Predictors of Depression after Stroke: A Systematic Review of Observational Studies. Stroke, 36, 2296-2301. https://doi.org/10.1161/01.STR.0000183622.75135.a4

[32] Johnson, J.L., Minarik, P.A., Nystrom, K.V., Bautista, C. and Gorman, M.J. (2006) Post Stroke Depression and Risk Factors: An Integrative Literature Review. Journal of Neuroscience Nursing, 38, 316-327. https://doi.org/10.1097/01376517-200609000-00008

[33] Mpembi, M.N., Mampunza ma Miezi, S., Peeters, A., et al. (2013) Sociodemographic Profile and Social Support for Post-Stroke Depression in Kinshasa: A Rehabilitation Based Cross-Sectional Study. Open Journal of Epidemiology, 3, 111-117. https://doi.org/10.4236/ojepi.2013.3318

[34] World Health Organization (2005) Steps Stroke Manual: WHO Stepwise Approach to Stroke Surveillance.

[35] Adoukonou, T.A., Vallat, J.M., Joubert, J., et al. (2010) Management of Stroke in Sub-Saharan Africa. Neurological Review, 166, 882-893. 